\title{
Upregulated ATF6 contributes to chronic intermittent hypoxia-afforded protection against myocardial ischemia/reperfusion injury
}

\author{
WEIKUN JIA, ZHAO JIAN, JINGWEI LI, LIN LUO, LIANG ZHAO, \\ YANG ZHOU, FUQIN TANG and YINGBIN XIAO
}

Department of Cardiovascular Surgery, Xinqiao Hospital, Third Military Medical University, Chongqing 400037, P.R. China

Received April 20, 2015; Accepted March 7, 2016

DOI: 10.3892/ijmm.2016.2535

\begin{abstract}
In the present study, we investigated the role of activating transcription factor 6 (ATF6) in the mechanism by which chronic intermittent hypoxia $(\mathrm{CIH})$ increases tolerance to myocardial ischemia/reperfusion (I/R). Experiments were conducted using a rat model of $\mathrm{I} / \mathrm{R}$ injury in vivo and isolated Langendorff-perfused rat hearts ex vivo. The role of Akt in this process was also investigated in vitro using rat myoblast H9c2 cells. Cell viability was measured using a cell counting kit-8 assay. Lactate dehydrogenase (LDH) and creatine kinase cardiac isoenzyme activity were also measured as markers of cellular damage. ATF6, Akt and phosphorylated (p)-Akt expression was analyzed by western blot analysis. RNA interference (RNAi) was used to suppress ATF6 expression. We noted that ATF6 expression in the ventricular myocardium was significantly increased in rats exposed to CIH. Furthermore, we noted that $\mathrm{CIH}$ preserved cardiac function after $\mathrm{I} / \mathrm{R}$ in vivo and improved post-ischemic recovery of myocardial performance in isolated rat hearts. ATF6 and p-Akt expression was upregulated in cultured $\mathrm{H} 9 \mathrm{c} 2$ cells exposed to chronic mild hypoxia compared with those cultured under normoxic conditions. Chronic mild hypoxia attenuated subsequent simulated I/R injury in H9c2 cells (48 h), as evidenced by increased cell viability and decreased LDH activity. By contrast, decreased cell viability and increased LDH activity were observed in siRNA-ATF6-transfected H9c2 cells, with a concomitant reduction in p-Akt levels. These results indicated that ATF6 upregulation is involved in the mechanism by which $\mathrm{CIH}$ attenuates myocardial I/R injury, possibly through upregulation of p-Akt, which is a key regulator of cardiomyocyte survival.
\end{abstract}

Correspondence to: Dr Yingbin Xiao or Dr Zhao Jian, Department of Cardiovascular Surgery, Xinqiao Hospital, Third Military Medical University, 183 Xinqiao Street, Chongqing 400037, P.R. China E-mail: xiaoyb@tmmu.edu.cn

E-mail: zhao.j@tmmu.edu.cn

Key words: chronic intermittent hypoxia, ischemia/reperfusion injury, activating transcription factor 6 , Akt

\section{Introduction}

Chronic hypoxia $(\mathrm{CH})$ occurs in individuals living in high altitude areas as well as in individuals with cyanotic congenital heart disease (such as Tetralogy of Fallot) and coronary artery disease. A previous epidemiological study has revealed that populations living at high altitude are less prone to chronic ischemic heart disease and have lower rates of mortality from heart disease (1). Clinical observation has noted long-term survival with rare occurrences of heart failure in children with cyanotic congenital heart defects. Furthermore, in our experience these children are able to tolerate hypoxic-ischemic injury caused by cardiac surgery that would likely cause myocardial necrosis in children non-cyanotic heart defects (2). Moreover, several animal experimental studies have demonstrated that myocardial chronic intermittent hypoxia $(\mathrm{CIH})$ is associated with more efficient metabolism, increased coronary vasculature and tolerance to acute hypoxic-ischemic injury, such as limitation of infarct size (3), improved recovery of ventricular systolic function $(4,5)$ and protection against ischemia/reperfusion (I/R)-induced ventricular arrhythmia (6). Although $\mathrm{CIH}$ induces a variety of adaptive changes in the myocardium that play a crucial role in this protective phenomenon, including the regulation of adenosine triphosphate (ATP)-sensitive $\mathrm{K}^{+}$ channels $(7,8)$, reactive oxygen species (9), nitric oxide (10), various protein kinases $(11,12)$, apoptosis (13) and pathways mediated by hypoxia inducible factor (14), details of the underlying molecular mechanisms remain to be elucidated.

Activating transcription factor 6 (ATF6), a key transcriptional activator involved in maintaining cellular homeostasis, is a 670-amino acid endoplasmic reticulum (ER) transmembrane protein that is cleaved in response to ER stress. The cleaved $\mathrm{N}$-terminal fragment translocates to the nucleus and activates ER stress response genes. A microarray study using mouse hearts showed that ATF6 activation induces the expression of almost 400 genes (15), many of which may serve protective roles. A previous study has revealed that ATF6 $\alpha$ modulates ER function to protect cells against chronic stress (16), which suggests that ATF6 mediates cytoprotective and pro-survival functions. A previous study (17) using a transgenic mouse model indicated that ATF6 activation prior to ischemia exerts protective effects against ischemia and/or reperfusion damage. Furthermore, we 
have previously demonstrated that the cardiac ER stress response is activated by $\mathrm{CIH}$ stress and that ATF6 $\alpha$ is continuously activated in primary human cardiomyocytes and rat myoblast $\mathrm{H} 9 \mathrm{c} 2$ cells (18). Several studies have also demonstrated the importance of the serine/threonine-specific protein kinase, Akt (also known as protein kinase B), in cardiomyocyte survival (19), which is effected through Ser473 phosphorylation (20), thus contributing to cardioprotection $(21,22)$. Activation of ATF6 positively regulates mammalian target of rapamycin (mTOR)C2-mediated phosphorylation of Akt at Ser473, which is required for full activity of Akt (23); however, the involvement of Akt in the cardioprotective effects exerted by ATF6 against myocardial I/R injury following $\mathrm{CIH}$ remain to be elucidated. Binding immunoglobulin protein (BiP), also known as heat shock protein 70, has been shown to be downstream of ATF6 in the response to chronic stress in the ER (24). Analysis of BiP should thus provide evidence that ATF6 has been activated.

In the present study, the role of ATF6 in the mechanism by which $\mathrm{CIH}$ increases tolerance to myocardial I/R was investigated using both in vivo and ex vivo models as well as a cultured cardiomyocyte model system. The role of Akt in this process was also investigated in a cultured cardiomyocyte model system.

\section{Materials and methods}

Animals and experimental protocol. Male Sprague-Dawley rats (3 weeks old, 140-180 g) were obtained from the Animal Center of Xinqiao Hospital at the Third Military Medical University (Chongqing, China).

Animals were used in order to investigate the following: i) the effects of global I/R injury simulated in ex vivo rat hearts subjected to normoxic perfusion $(n=6)$ and exposed to $\mathrm{CIH}$ $(n=6)$ using the Langendorff-perfusion system; ii) determination of regional I/R injury induced by coronary ligation and subsequent reperfusion of rat heart tissues subjected to normoxic perfusion $(n=6)$ and exposed to $\mathrm{CIH}(\mathrm{n}=7)$; iii) determination of the expression of ATF6 in heart tissues of rats subjected to normoxic perfusion $(n=5)$ and exposed to $\mathrm{CIH}(\mathrm{n}=5)$.

All experiments involving the use of animals performed as part of this study were conducted with the approval of the Third Military Medical University Animal Care and Ethics Committee.

Exposure to chronic hypoxia. Rats were randomly assigned to either the normoxia group or the CIH group. The initial body weight was measured using an electronic scale (DST673; SuHang Co. Ltd., Suzhou, China) immediately before exposure to hypoxia. Rats in the $\mathrm{CIH}$ group were housed for 4 weeks in a hypobaric chamber (equivalent to an altitude of 5,000 m, with a barometric pressure of $404 \mathrm{mmHg}, \mathrm{PO}_{2}=84.98 \mathrm{mmHg}$ ). Barometric pressure in the chamber was adjusted weekly (equivalent to an altitude of 3,000 m over a period of $1 \mathrm{~h}$ ) for cage maintenance. Age-matched rats in the normoxia group were housed under normoxic conditions for the duration of the experiments. All animals had free access to water and a standard laboratory diet. At the end of the fourth week, the body weight of the animals was measured and a blood sample was collected from the abdominal aorta to determine the blood gas parameters using a blood gas analyzer (I-STAT 300; Abbott Laboratories, Abbott Park, IL, USA).
Examining I/R using isolated rat hearts. Rats were anesthetized with pentobarbital sodium $[50 \mathrm{mg} / \mathrm{kg}$ administered intraperitoneally (i.p.)]. Following a laparotomy and thoracotomy, heparin $(1,000 \mathrm{IU} / \mathrm{kg}$ body weight) was injected intravenously. Hearts were rapidly excised and transferred into cold $\left(4^{\circ} \mathrm{C}\right)$, heparinized Krebs-Henseleit $(\mathrm{K}-\mathrm{H})$ perfusate $[\mathrm{NaCl}$ (118 mmol/l), $\mathrm{NaHCO}_{3}(25 \mathrm{mmol} / \mathrm{l}), \mathrm{KCl}(4.7 \mathrm{mmol} / \mathrm{l}), \mathrm{MgSO}_{4}$ (1.2 mmol/l), $\mathrm{KH}_{2} \mathrm{PO}_{4}(1.2 \mathrm{mmol} / \mathrm{l})$, glucose (11 mmol/l), $\mathrm{CaCl}_{2}$ ( $2.5 \mathrm{mmol} / \mathrm{l})]$. The hearts were connected to Langendorff apparatus via the aorta within $30 \mathrm{sec}$ of excision and subsequently perfused with $\mathrm{K}-\mathrm{H}$ perfusate in a retrograde manner at constant pressure $\left(80 \mathrm{~cm} \mathrm{H}_{2} \mathrm{O}\right)$. The perfusate was bubbled with gas (95\% oxygen, $5 \%$ carbon dioxide) to yield a $\mathrm{pH}$ of 7.4 at $37^{\circ} \mathrm{C}$ throughout the experiment. A water-filled latex balloon connected to a pressure transducer was inserted into the left ventricle (LV) through the left atrium and the mitral annulus. Left ventricular developed pressure (LVDP) was monitored by an amplifier. During the period of measurement, the balloon volume was adjusted to produce a left ventricular end diastolic pressure (LVEDP) of $6 \mathrm{mmHg}$. After a stabilization period (approximately $20 \mathrm{~min}$ ), the isolated heart was subjected to global normothermic ischemia for $30 \mathrm{~min}$ and then perfused for $1 \mathrm{~h}$. The effluent was collected for lactate dehydrogenase (LDH) activity assays at $60 \mathrm{~min}$ after reperfusion. At the end of the reperfusion, the hearts were removed from the perfusion cannula and stored at $-80^{\circ} \mathrm{C}$ for triphenyl tetrazolium chloride (TTC) staining, immunofluorescence staining and western blot analysis.

In vivo rat model of $I / R$ injury. Animals were anesthetized with pentobarbital sodium [50 $\mathrm{mg} / \mathrm{kg}$ i.p.] and mechanically ventilated with air $(10 \mathrm{ml} / 100 \mathrm{~g}$ body weight; 80 breaths $/ \mathrm{min})$. The barometric pressure was changed using a face mask; the breath ratio was 1:2. A left thoracotomy was undertaken between the third and fourth ribs. The heart was exposed, and a 6-0 Prolene suture was passed under the left anterior descending coronary artery (LAD) 2-3 mm below the left atrium using a needle. A piece of polyethylene tubing was placed between the LAD and the suture before the LAD was ligated for $30 \mathrm{~min}$, followed by coronary reperfusion for $24 \mathrm{~h}$ by releasing the ligature. The chest cavity was closed and the animal was gradually detached from the respirator. At the end of the experiment, the rats were sacrificed by injection of $3 \mathrm{ml} \mathrm{2.6 \%}$ potassium chloride and re-thoracotomized to allow for the collection of blood samples into ethylenediaminetetraacetic acid (EDTA) tubes via the inferior vena cava (IVC) for creatine kinase (CK)-cardiac isoenzyme CK-MB and $\mathrm{LDH}$ analysis. The hearts were excised and frozen at $-20^{\circ} \mathrm{C}$ for myocardial infarct size assessment.

Transthoracic echocardiography. Echocardiographic measurements were performed prior to ischemic injury and at $24 \mathrm{~h}$ after reperfusion. The rats were anesthetized with pentobarbital (50 mg/kg i.p.) and heart rates were maintained at 200-400 beats/min. Transthoracic 2D-guided M-mode echocardiography was performed using a Vevo 2100 Imaging System (VisualSonics Inc., Toronto, ON, Canada) with a 13-24 MHz scan probe (MS250). Ejection fraction (EF) and fractional shortening (FS) were calculated according to standard formulas as indicators of ventricular function. 
TTC staining. Frozen hearts were first partially thawed and then frozen sectioned (thickness, $1 \mathrm{~mm}$ ) perpendicular to the longitudinal axis. The remaining heart tissues were used for western blot analysis. Sections were incubated in $1 \%$ TTC in phosphate-buffered saline (PBS) solution at $37^{\circ} \mathrm{C}$ for $15 \mathrm{~min}$ and then fixed in $4 \%$ formalin solution overnight at $4^{\circ} \mathrm{C}$. Sections were then placed on glass slides and photographed. The infarction area for each section was determined using ImageJ software and the infarct size was expressed as a percentage of the total cross-sectional area of the heart.

LDH and $C K-M B$ activity. LDH and CK-MB activity in the collected blood samples was assayed using a Lactate Dehydrogenase test kit, and a Creatine Kinase MB test kit (both from Ruiyuan Biotechnology Co., Ltd., Ningbo, China), respectively. The results were analyzed using a Beckman Coulter Chemistry Analyzer (AU-5800; Beckman Coulter Inc., Tokyo, Japan).

Cell culture and experimental protocols. H9c2 cells were obtained from the American Type Culture Collection (ATCC, Rockville, MD, USA) and cultured in Dulbecco's modified Eagle's medium (DMEM) supplemented with $10 \%$ fetal bovine serum (FBS) (both from Invitrogen, Carlsbad, CA, USA).

After $24 \mathrm{~h}$, the H9c 2 cells were randomly divided into the normoxia and mild hypoxia groups. The cells were cultured in an incubator (Thermo 3131; Thermo Fisher Scientific, Waltham, MA, USA) in which the fraction of inspired oxygen $\left(\mathrm{FiO}_{2}\right)$ levels were 21 and $13 \%$, respectively, as has been previously described (8). At 0, 12, 24, 48 and $72 \mathrm{~h}$, ATF6 expression was assayed. The time point at which ATF6 expression reached a maximum was used in subsequent experiments to investigate the protective effect of ATF6 on cells subjected to I/R injury. The experimental groups were as follows: i) normoxia $+\mathrm{I} / \mathrm{R}$; ii) hypoxia + I/R; iii) hypoxia + control-siRNA + I/R, iv) hypoxia + ATF6-siRNA + I/R. I/R was simulated by placing cells in ischemia buffer $\left[\mathrm{CaCl}_{2}(1.13 \mathrm{mmol}), \mathrm{KCl}(5 \mathrm{mM})\right.$, $\mathrm{KH}_{2} \mathrm{PO}_{4}(0.3 \mathrm{mmol}), \mathrm{MgCl}_{2}(0.5 \mathrm{mmol}), \mathrm{MgSO}_{4}(0.4 \mathrm{mmol})$, $\mathrm{NaCl}(128 \mathrm{mmol}), \mathrm{NaHCO}_{3}(4 \mathrm{mmol}), \mathrm{HEPES}(10 \mathrm{mmol}) ;$ $\mathrm{pH}$ 6.8], which was previously equilibrated in the anoxia chamber $\left(95 \% \mathrm{~N}_{2}, 5 \% \mathrm{CO}_{2}, 37^{\circ} \mathrm{C}\right)$ for $1 \mathrm{~h}$. Subsequently, cells were reperfused for $3 \mathrm{~h}$ under normal culture conditions. There were five replicates in each group. Cell viability assays for all groups were performed at $3 \mathrm{~h}$ after reperfusion.

Transfection of siRNA. H9c2 cells were seeded in 24-well plates $\left(4 \times 10^{4}\right.$ cells/well $)$ and transfected when the cells reached approximately $50 \%$ confluence. Each well was transfected with siRNA targeted against rat ATF6 (5'-ACCACAAGACCG AAGATG-3') or a negative control (5'-GCCTGCCGTCCA AAGTTGTAA-'3) (both from Shanghai GenePharma Co., Ltd., Shanghai, China) with 5\% FBS using Lipofectamine 2000 Transfection reagent (Invitrogen) according to the manufacturer's protocol. After $24 \mathrm{~h}$, the cells were switched to a medium containing $5 \%$ fetal calf serum for use in subsequent experiments.

Cell viability assessment. Cell viability was assessed using a cell counting kit-8 (CCK-8; Boster Biological Technology Ltd., Wuhan, China) and studying LDH release into the culture medium. For the CCK-8 assay, CCK-8 solution (10 $\mu \mathrm{l})$ was added to each well and the plate was incubated at $37^{\circ} \mathrm{C}$ for $4 \mathrm{~h}$. Absorbance was measured at $450 \mathrm{~nm}$ using the VICTOR $^{\text {TM }}$ X2 Multilabel Plate reader (PerkinElmer, Inc., Waltham, MA, USA) with a reference wavelength of $650 \mathrm{~nm}$. LDH activity was assayed using a Lactate Dehydrogenase test kit (Ruiyuan Biotechnology Co., Ltd.,) and analyzed with a Beckman Coulter Chemistry Analyzer (AU-5800; Beckman Coulter Inc.).

Immunofluorescence staining. Immunofluorescence assays for the detection of ATF6 were performed using DAPI on the frozen sections of the ventricular myocardium. The sections were blocked with $1 \%$ bovine serum albumin in PBS, and then incubated overnight at $4{ }^{\circ} \mathrm{C}$ with a mouse monoclonal antibody against ATF6 $\alpha$ (ab11909, 1:50; Abcam, Cambridge, MA, USA). Immunoreactivity was detected by incubating the sections for $40 \mathrm{~min}$ at $37^{\circ} \mathrm{C}$ with a FITC-labeled goat antimouse IgG (A0568, 1:50; Beyotime Institute of Biotechnology, Beijing, China) secondary antibody, and images of immunofluorescence staining were obtained by laser scanning confocal microscopy (TCS SP5; Leica, Mannheim, Germany).

Western blot analysis. Total proteins were extracted from ventricular myocardial tissues or cultured cells, which were homogenized in an in ice-cold lysis buffer (T-TER Tissue Protein Extraction Reagent; Thermo Fisher Scientific) containing phosphatase and protease inhibitors. Extracts were centrifuged at 15,000 x g, at $4^{\circ} \mathrm{C}$ for $5 \mathrm{~min}$, and protein concentration was measured using the Bradford assay (Bio-Rad, Hercules, CA, USA). Lysates were separated by $10 \%$ sodium dodecyl sulfate-polyacrylamide gel electrophoresis (SDS-PAGE) and transferred to polyvinylidene difluoride (PVDF) membranes (Roche, Mannheim, Germany). The membranes were blocked (SuperBlock blocking buffer in TBS, with $0.5 \%$ Tween-20) for $2 \mathrm{~h}$ at $37^{\circ} \mathrm{C}$. Primary antibodies were used in western blot analysis according to the manufacturer's instructions. The membranes were incubated overnight with antibodies against ATF6 $\alpha$ (Abcam), Akt (Cat. no. 2966), phosphorylated (p)-Akt (Ser473; Cat. no. 8200), BiP (Cat. no. 3177) (all from Cell Signaling Technology, Inc., Beverly, MA, USA), GAPDH (ab8245; Abcam) and $\beta$-actin (A1978; Sigma, St. Louis, MO, USA) (all 1:500 in SuperBlock blocking buffer in TBS, with $0.5 \%$ Tween-20) at $4^{\circ} \mathrm{C}$ overnight. After washing six times with Tris-buffered saline ( $5 \mathrm{~min} / \mathrm{wash}$ ), the blots were incubated with a horseradish peroxidase-conjugated goat anti-rat IgG (sc-2041, 1:1,000; Santa Cruz Biotechnology, Inc. Santa Cruz, CA, USA) for $1 \mathrm{~h}$ at $37^{\circ} \mathrm{C}$. The blots were washed three times with Trisbuffered saline and antibody binding was detected with an imaging system (Kodak Gel Logic 212; Kodak, Rochester, NY, USA). The blots were analyzed by Quantity One software (Bio$\mathrm{Rad})$.

Statistical analysis. All data are expressed as the means \pm standard error of the means (SEM). Data were analyzed by SPSS 17.0. Statistically meaningful differences were determined using independent Student's t-tests or paired t-tests. A P-value $<0.05$ was considered to indicate a statistically significant difference.

\section{Results}

CIH changes physical parameters. Although there was no significant difference in the initial body weight of the rats 
A

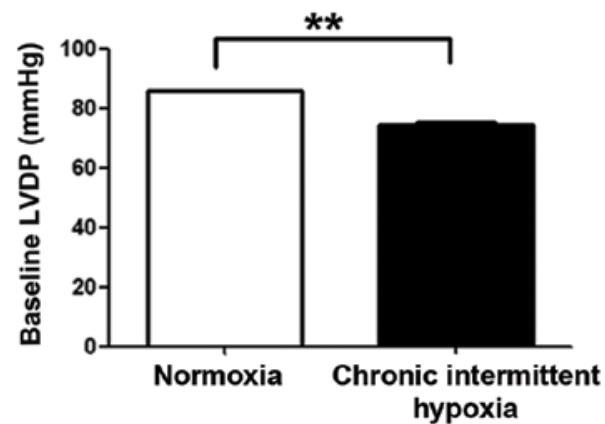

B

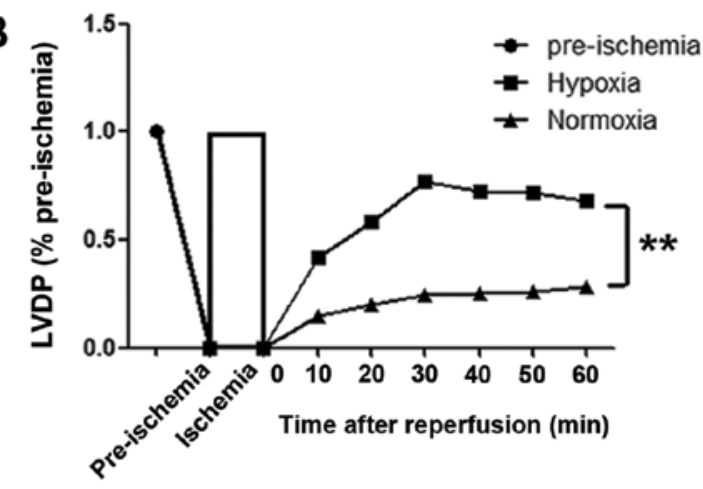

C

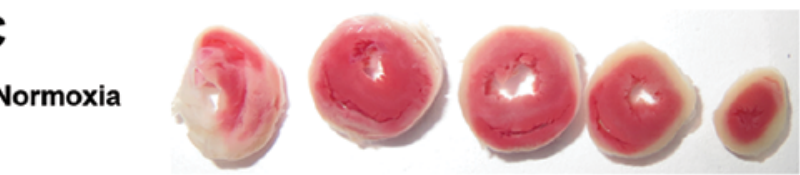

Chronic hypoxia

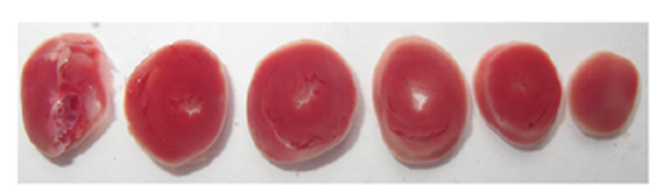

D

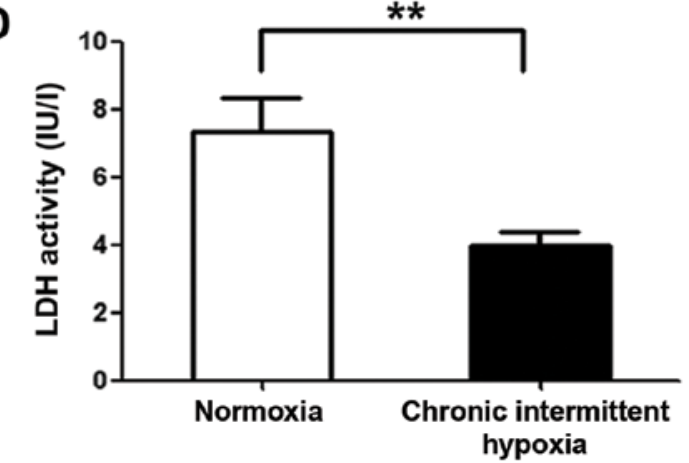

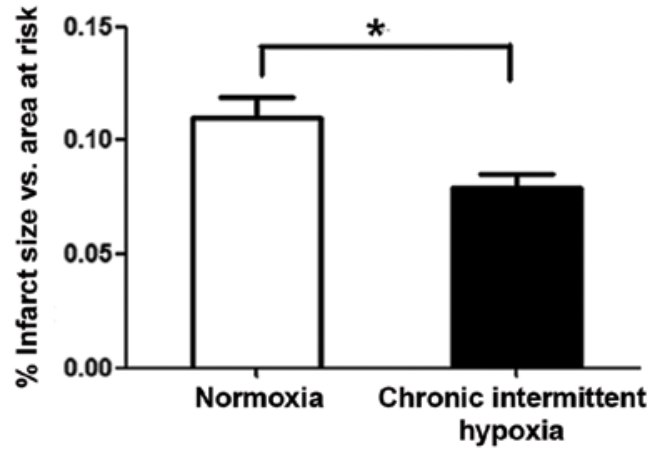
hypoxia

Figure 1. Chronic intermittent hypoxia (CIH) improves cardiac function recovery after ischemia/reperfusion (I/R) in isolated rat hearts. After 20 min of stabilization with Krebs-Henseleit (K-H) perfusate, the hearts were subjected to 30 min of global ischemia and $1 \mathrm{~h}$ of reperfusion. (A) Left ventricular developed pressure (LVDP) before ischemia. (B) LVDP recovery (percentage of pre-ischemic LVDP). (C) Representative sections for TTC staining (left) and the average infarct size vs. total area at risk (right). (D) CIH decreased I/R-induced necrosis, as shown by lactate dehydrogenase (LDH) release in the effluent after 60 min of reperfusion. Data are represented as the means $\pm \mathrm{SEM}$ ( $\mathrm{n}=6$ rats/group). ${ }^{*} \mathrm{P}<0.05$ and ${ }^{* * *} \mathrm{P}<0.01$ vs. normoxia group.

prior to exposure to hypoxia, after 4 weeks of exposure the final body weight of the rats in the $\mathrm{CIH}$ group was significantly lower than those in the normoxia group $(\mathrm{P}<0.01)$ (Table I). Furthermore, the blood hemoglobin levels, hematocrit values, and the heart weight/body weight ratios of the CIH group were significantly higher than those of the normoxia group $(\mathrm{P}<0.01)$. In addition, arterial oxygen tension and oxygen saturation were significantly higher in the normoxia group compared with those in the CIH group (both $\mathrm{P}<0.01$ ).

CIH improves post-ischemic recovery of myocardial performance in isolated rat hearts. To examine the cardioprotective effects of $\mathrm{CIH}$, we monitored left ventricular function in Langendorff-perfused hearts subjected to $30 \mathrm{~min}$ of global ischemia followed by $60 \mathrm{~min}$ of reperfusion. The LVDP (preischemia) in the CIH group was markedly lower than that in normoxia group $(\mathrm{P}<0.01)$ (Fig. 1A). However, at all time points investigated during the reperfusion period, greater recovery of LVDP was observed in the CIH group compared with the normoxia group $(\mathrm{P}<0.01)$ (Fig. 1B). To assess the degree of myocardial injury following global ischemia, the infarct size
Table I. Physical parameters measured in the animals at the end of 4 weeks of exposure to normoxic or chronic hypoxic conditions.

\begin{tabular}{lcc}
\hline Parameter & Normoxia & Chronic hypoxia \\
\hline Number of rats (n) & 17 & 18 \\
Initial body weight $(\mathrm{g})$ & $161.24 \pm 11.58$ & $160.12 \pm 10.87$ \\
Final body weight $(\mathrm{g})$ & $311.34 \pm 7.06$ & $228.44 \pm 5.66^{\mathrm{a}}$ \\
Heart weight (mg) & $781.80 \pm 180.50$ & $924.40 \pm 384.30^{\mathrm{a}}$ \\
Heart/final body & $2.60 \pm 0.06$ & $4.04 \pm 0.12^{\mathrm{a}}$ \\
weight ratio (mg/g) & & \\
Hematocrit value $(\%)$ & $41.24 \pm 0.01$ & $57.11 \pm 0.01^{\mathrm{a}}$ \\
Hemoglobin (g/l) & $13.97 \pm 0.19$ & $19.08 \pm 0.32^{\mathrm{a}}$ \\
$\begin{array}{l}\text { Arterial oxygen tension } \\
\text { (mmHg) }\end{array}$ & $81.65 \pm 1.01$ & $45.94 \pm 0.69^{\mathrm{a}}$ \\
$\begin{array}{l}\text { Arterial oxygen saturation } \\
\text { (mmHg) }\end{array}$ & $93.53 \pm 0.61$ & $66.50 \pm 13.04^{\mathrm{a}}$ \\
\hline
\end{tabular}

Results are shown as the means \pm SEM. ${ }^{\text {a }}<0.01$ vs. the normoxia group. 
A

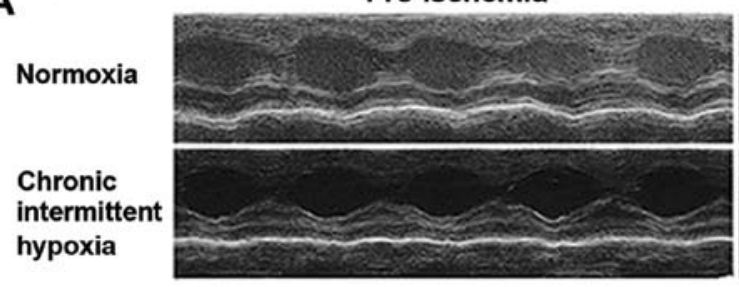

Post-reperfusion

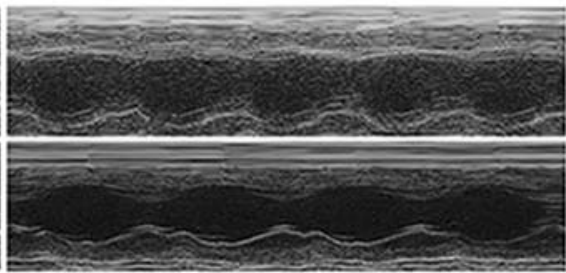

B

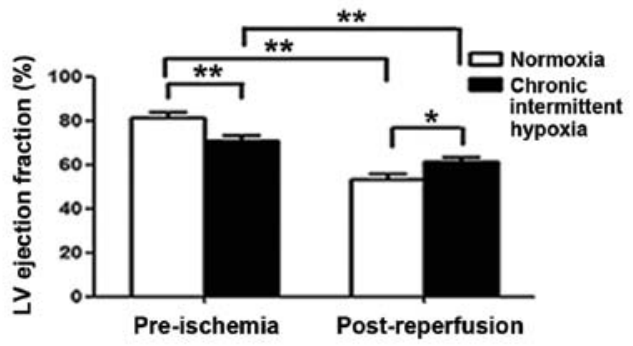

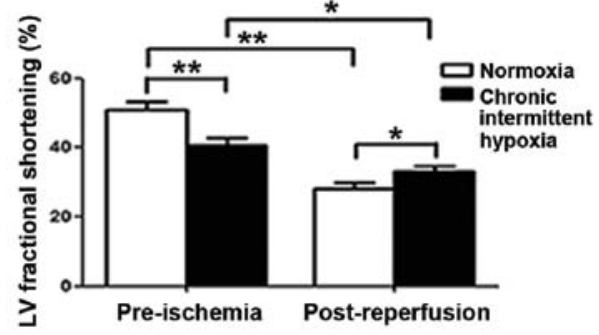

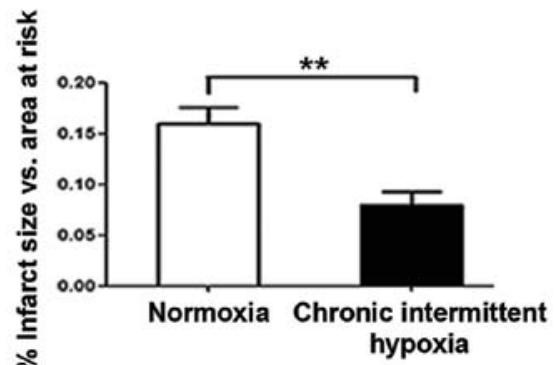

D

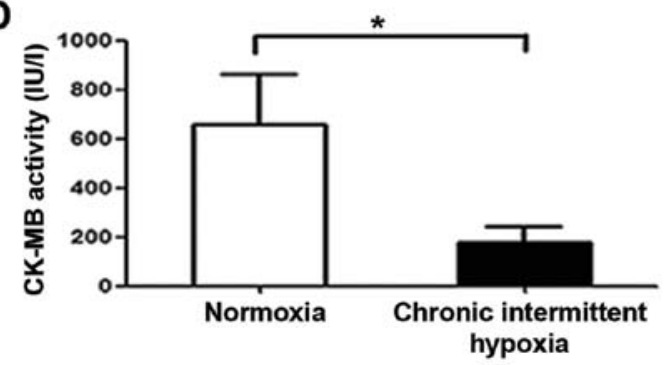

E

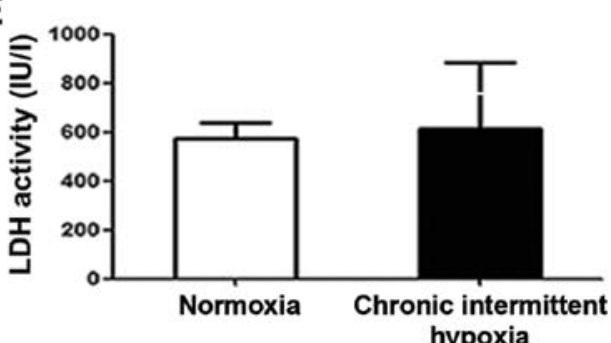

Figure 2. In vivo effects of chronic intermittent hypoxia (CIH) on left ventricular function following myocardial ischemia/reperfusion. (A) Representative echocardiographic images taken pre-ischemia and post-reperfusion. (B) Pre-ischemic and post-reperfusion (24 h) cardiac function: left ventricular ejection fraction (LVEF) (left) and left ventricular fractional shortening (LVFS) (right). (C) Average infarct size. (D) Post-reperfusion (24 h) creatine kinase (CK)-MB activity. (E) Post-reperfusion ( $24 \mathrm{~h}$ ) lactate dehydrogenase (LDH) activity. Data are represented as the means \pm SEM (CH group, $\mathrm{n}=7 ; \mathrm{N}$ group, $\mathrm{n}=6$ ). $\mathrm{P}<0.05$ vs. normoxia group. $\mathrm{P}<0.05$ and ${ }^{* * *} \mathrm{P}<0.01$.

of all reperfused hearts was determined, and LDH activity in the effluent at the end of reperfusion was assayed. Markedly smaller infarcts $(\mathrm{P}<0.05)$ and lower LDH activity in the effluent $(\mathrm{P}<0.01)$ were observed in the $\mathrm{CIH}$ group compared with the normoxia group (Fig. 1C and D).

$C I H$ preserves rat cardiac function after $I / R$ in vivo. Rats were subjected to I/R injury by $30 \mathrm{~min}$ LAD ligation followed by $24 \mathrm{~h}$ coronary reperfusion, and cardiac function was evaluated by echocardiography. We noted that pre-ischemic cardiac function was markedly lower in the $\mathrm{CIH}$ group than that in the normoxia group (Fig. 2A and B), although LV systolic function was markedly reduced in both the normoxia and $\mathrm{CIH}$ groups at $24 \mathrm{~h}$ after reperfusion compared with that observed pre-ischemia (Fig. 2B). However, we noted that the decrease in $\mathrm{EF}$ and $\mathrm{FS}$ in $\mathrm{CIH}$ rats was less than in the normoxia group. Notably, both the EF and the FS after I/R in the CIH group were higher than that in the normoxia group $(\mathrm{P}<0.01)$ (Fig. 2B), suggesting that $\mathrm{CIH}$ preserves cardiac function after I/R. Similarly, the infarct size measured at $24 \mathrm{~h}$ after reperfusion was greater in the normoxia group than that in the CIH group $(\mathrm{P}<0.01)$ (Fig. 2C). Furthermore, CK-MB activity following $\mathrm{I} / \mathrm{R}$ was noted as being significantly lower in the $\mathrm{CIH}$ group than in the normoxia group $(\mathrm{P}<0.05)$ (Fig. 2D), indicating less myocardial damage in the $\mathrm{CIH}$ group; however, there was no significant difference in LDH activity between the two groups $(\mathrm{P}>0.05)$ (Fig. 2E).

CIH induces ATF6 expression. Our previous study showed that ATF6 was overexpressed in human specimens and H9c2 
A

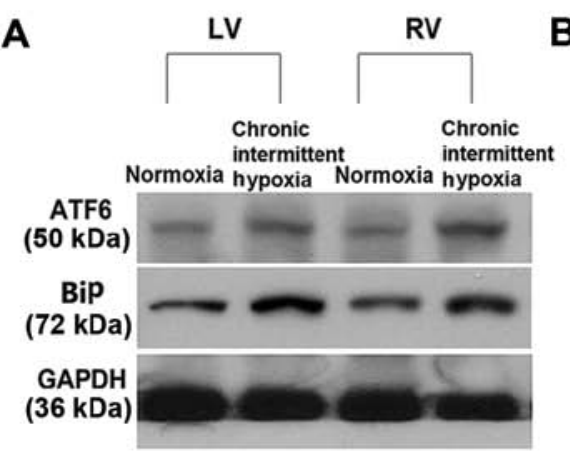

B

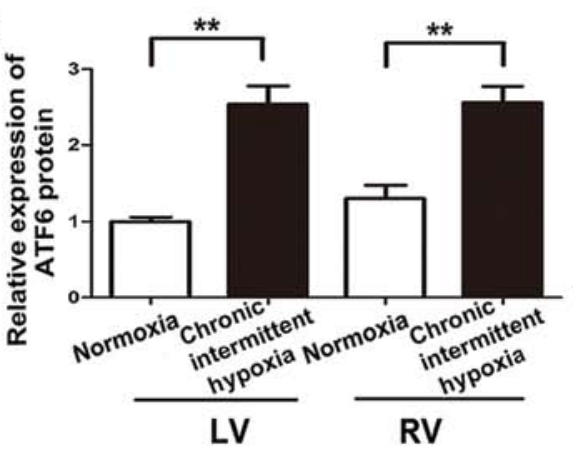

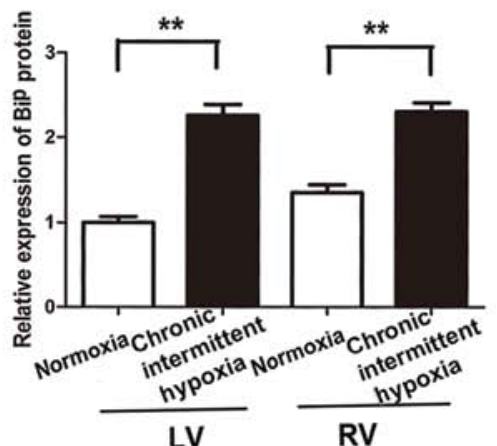

RV

LV
C
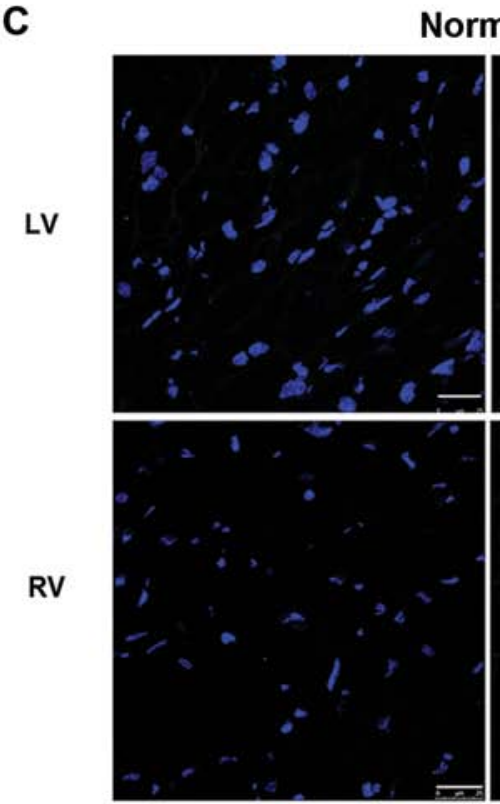

Normoxia
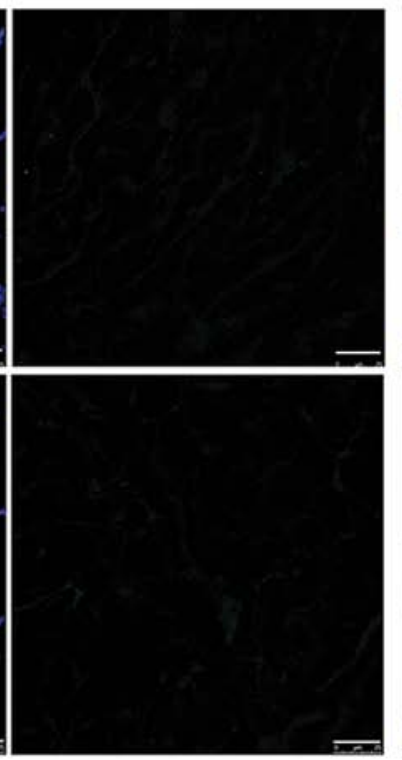
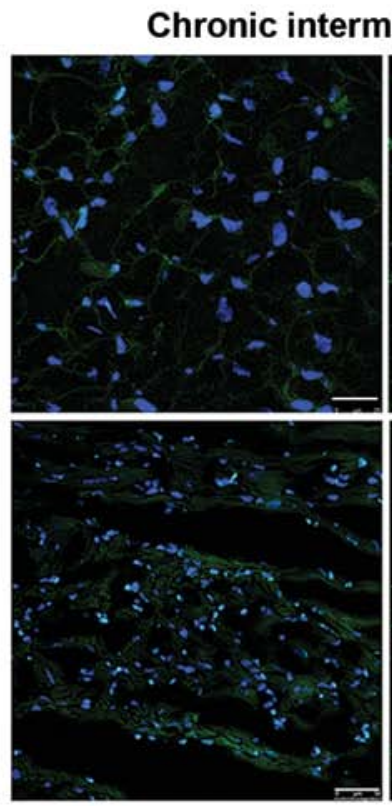
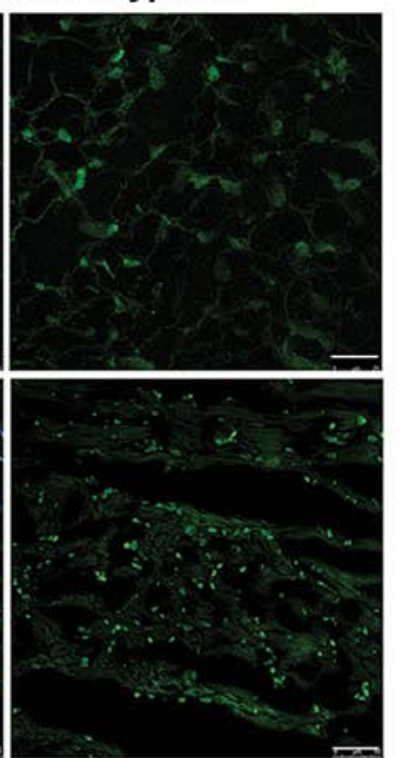

Figure 3. Cleaved activating transcription factor 6 (ATF6) expression in rat hearts. (A) Representative images of western blot analysis of cleaved ATF6, binding immunoglobulin protein $(\mathrm{BiP})$ and glyceraldehyde 3-phosphate dehydrogenase (GADPH) protein expression in rat myocardial tissue under normoxic or hypoxic conditions. (B) Quantification of cleaved ATF6 and BiP protein levels (normalized to GADPH protein levels). Representative data from five independent experiments are shown. ${ }^{* *} \mathrm{P}<0.01$ vs. normoxia group. (C) Immunofluorescence staining of the left ventricle (LV) and the right ventricle (RV) of rat hearts for ATF6 protein expression (green) under hypoxic or normoxic conditions; cell nuclei were counterstained with DAPI (blue). Scale bar, 25 mm.

cells under anoxic conditions (18). To confirm this effect in the present study, cleaved ATF6 $\alpha$ expression in tissue samples taken from the right ventricle (RV) and LV of rat hearts exposed to normoxic and chronic intermittent hypoxic conditions was determined using western blot analysis. The samples were taken immediately after removing the animals from the hypobaric chamber. Myocardial cleaved ATF6 $\alpha$ (50 kDa) protein expression was significantly higher in the $\mathrm{CIH}$ group compared with the normoxia group $(\mathrm{P}<0.01)$ (Fig. 3A and $\mathrm{B}$ ), with no statistically significant difference noted between the expression in the LV and RV in the CIH group ( $\mathrm{P}>0.05$ ) (Fig. 3B). Similar results were noted for $\mathrm{BiP}$ expression, which was increased in the CIH group in both the LV and RV in comparison with the normoxia group. Immunofluorescence staining also revealed a significant increase in ATF6 expression both in the LV and the $\mathrm{RV}$ induced by CIH (Fig. 3C).

Cardioprotective effects of ATF6 against myocardial I/R injury are induced by mild hypoxia. The cardioprotective effects of ATF6 against myocardial I/R injury caused by $\mathrm{CH}$ were first investigated by western blot analysis of cleaved ATF6 protein expression in rat myocardial $\mathrm{H} 9 \mathrm{c} 2$ cells subjected to chronic mild hypoxia, in a previous study (8). As shown in Fig. 4A, endogenous cleaved ATF6 protein expression was significantly upregulated in $\mathrm{H} 9 \mathrm{c} 2$ cells after $24 \mathrm{~h}$ exposure to mild hypoxia $(\mathrm{P}<0.05)$, with continued upregulation after $48 \mathrm{~h}$ and a high level of expression maintained up to $72 \mathrm{~h}(\mathrm{P}<0.01)$. Similar results were also noted in relation to $\mathrm{BiP}$ expression, which increased up to $72 \mathrm{~h}$.

Subsequently, the effect of chronic mild hypoxia on sI/R-induced cellular injury was evaluated. H9c2 cells exposed to hypoxia for $48 \mathrm{~h}$ (the time point determined for high ATF6 expression) were subjected to ischemia for $1 \mathrm{~h}$ followed by reperfusion for $3 \mathrm{~h}$, as previously described (25). H9c2 cells cultured under normoxic conditions served as a control. Chronic mild hypoxia increased $\mathrm{H} 9 \mathrm{c} 2$ cell viability by $38 \%$ and reduced LDH activity compared with that detected in cells cultured under normoxic conditions (both $\mathrm{P}<0.01$ ) (Fig. 4C and D, respectively).

To further determine the cardioprotective effects of ATF6 induced by chronic mild hypoxia against subsequent I/R damage, cleaved ATF6 expression was blocked in H9c2 cells by transfection with siRNA-ATF6 prior to hypoxic exposure. Suppression of cleaved ATF6 expression was confirmed, at $48 \mathrm{~h}$ 
A

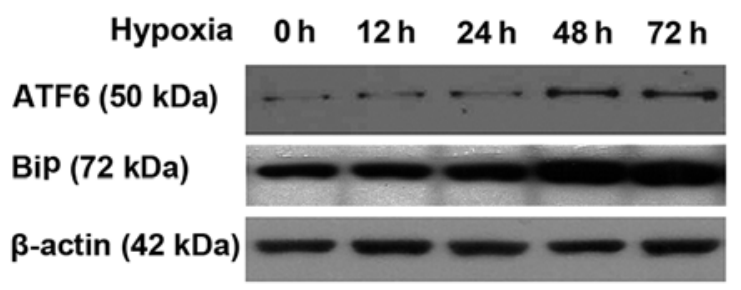

B

Hypoxia $0 \mathrm{~h} \quad 12 \mathrm{~h} \quad 24 \mathrm{~h} \quad 48 \mathrm{~h} \quad 72 \mathrm{~h}$

p-Akt (60 kDa)

Akt (60 kDa)

$\beta$-actin (42 kDa)

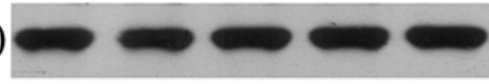

C

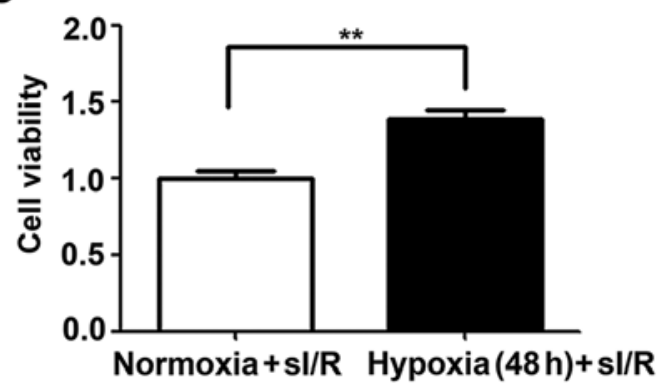

하일
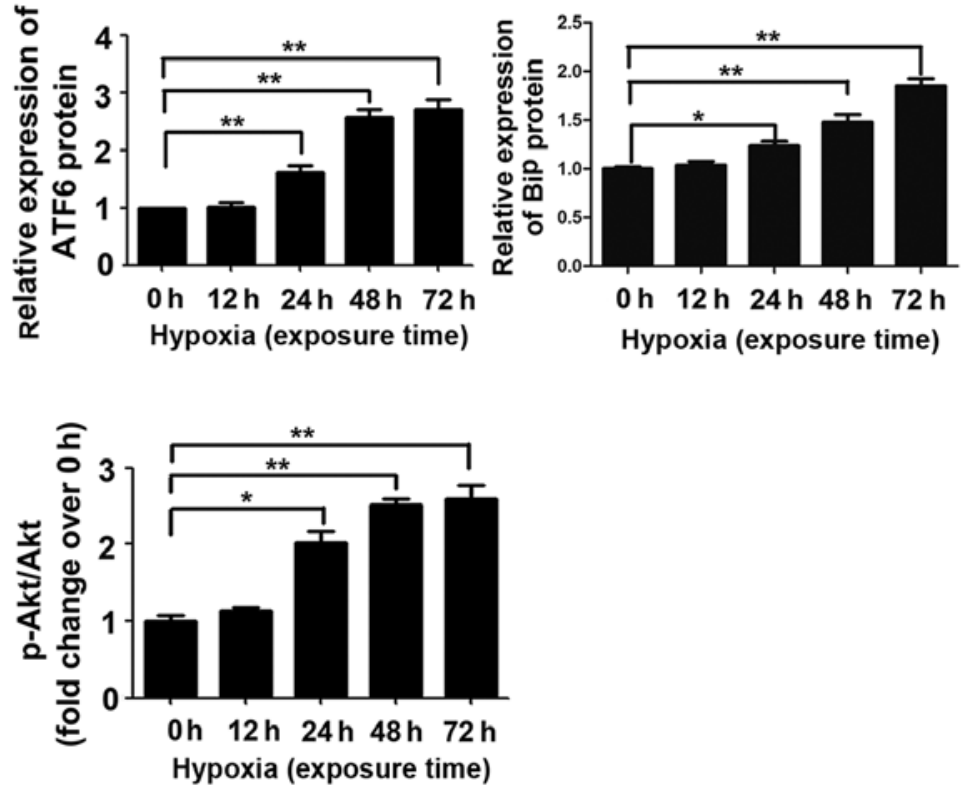

D

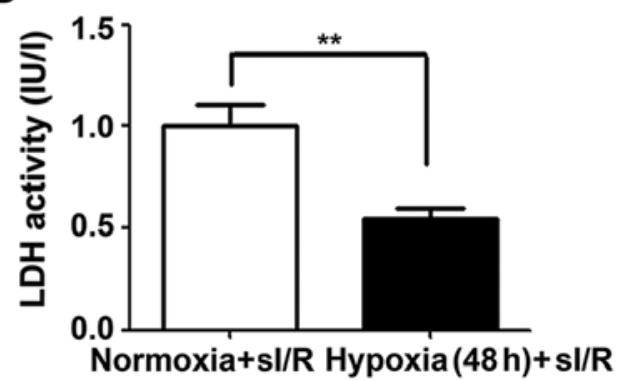

Figure 4. Cleaved activating transcription factor 6 (ATF6) and Akt expression and effects on simulated ischemia/reperfusion (sI/R) injury induced in H9c2 cells subjected to mild hypoxia. (A) Representative expression of cleaved ATF6 and $\beta$-actin protein in H9c2 cells cultured under normoxic or hypoxic conditions for $0,12,24,48$ and $72 \mathrm{~h}$ (left); quantification of cleaved ATF6 and binding immunoglobulin protein (BiP) protein levels (normalized to $\beta$-actin protein levels) (right, ${ }^{*} \mathrm{P}<0.05$ vs. $0 \mathrm{~h} ;{ }^{* *} \mathrm{P}<0.01$ vs. $0 \mathrm{~h}$ ). (B) Representative expression of Akt, p-Akt and $\beta$-actin protein in H9c2 cells cultured under normoxic or hypoxic conditions for $0,12,24,48$ and $72 \mathrm{~h}$ (left); quantification of p-Akt protein levels (normalized to total Akt protein levels) (right, "P<0.05 vs. 0 h; ${ }^{* *} \mathrm{P}<0.01$ vs. $0 \mathrm{~h}$ ). (C) Effect of mild hypoxia on the viability of $\mathrm{H} 9 \mathrm{c} 2$ cells subjected to ischemia ( $\left.1 \mathrm{~h}\right)$ followed by reperfusion ( $\left.3 \mathrm{~h}\right)$. Representative data from five independent experiments are presented as the means $\pm \mathrm{SEM}\left({ }^{* *} \mathrm{P}<0.01\right.$ vs. normoxia group). (D) Effect of chronic mild hypoxia on lactate dehydrogenase $(\mathrm{LDH})$ activity in $\mathrm{H} 9 \mathrm{c} 2$ cells subjected to ischemia $(1 \mathrm{~h})$ followed by reperfusion $(3 \mathrm{~h})$. Representative data from five independent experiments are presented as the means $\pm \operatorname{SEM}\left({ }^{* *} \mathrm{P}<0.01\right.$ vs. normoxia group).

after exposure to mild hypoxia, by western blot analysis. We also noted a decrease in BiP expression in comparison to the siRNA and hypoxic controls ( $\mathrm{P}<0.01)$ (Fig. 5A). Following I/R, the viability of siRNA-ATF6 transfected H9c2 cells was also significantly reduced (by 35\%) $(\mathrm{P}<0.01)$ (Fig. 5C), while LDH activity was significantly increased (by 1.2-fold) compared with siRNA-control transfected cells $(\mathrm{P}<0.01)$ (Fig. 5D).

ATF6 exerts cardioprotective effects against I/R injury through upregulation of $p$-Akt. To elucidate the molecular mechanism by which ATF6 mediates cardioprotection against I/R injury induced by $\mathrm{CH}$, the Akt signaling pathway was examined. Firstly, Akt expression was investigated in H9c2 cells cultured under chronic mild hypoxia conditions. After $24 \mathrm{~h}$ of hypoxia, p-Akt expression was observed, with expression peaking after $48 \mathrm{~h}$ (Fig. 4B). Of note, increased Akt expression was consistent with the changes observed in cleaved ATF6 protein levels. Subsequently, the influence of siRNA-ATF6-mediated suppression of cleaved ATF6 on Akt expression in H9c2 cells was investigated. Western blot analysis showed that transfection of H9c2 cells with ATF6-siRNA suppressed hypoxia-induced p-Akt expression compared with siRNA-control transfected cells (Fig. 5B).

\section{Discussion}

In the present study, $\mathrm{CIH}$ induced high expression of cleaved ATF6, which was associated with significantly attenuated myocardial infarct size and increased cardiac tolerance to acute I/R injury both in vivo and ex vivo. Furthermore, mild hypoxiamediated cytoprotection against simulated I/R in H9c2 cells was demonstrated by improved cellular viability and increased p-Akt and BiP levels. Thus, the results of the present study demonstrated that exposing rats to $\mathrm{CIH}$ conferred resistance to subsequent $\mathrm{I} / \mathrm{R}$ injury of the myocardium by upregulating cleaved ATF6 and increased Akt pathway signaling.

Previous studies have demonstrated that $\mathrm{CIH}$ confers longlasting cardioprotection against acute I/R injury $(7,10,26)$. Furthermore, clinical observations and epidemiological studies have implicated $\mathrm{CIH}$ in cardioprotection (2). These observa- 

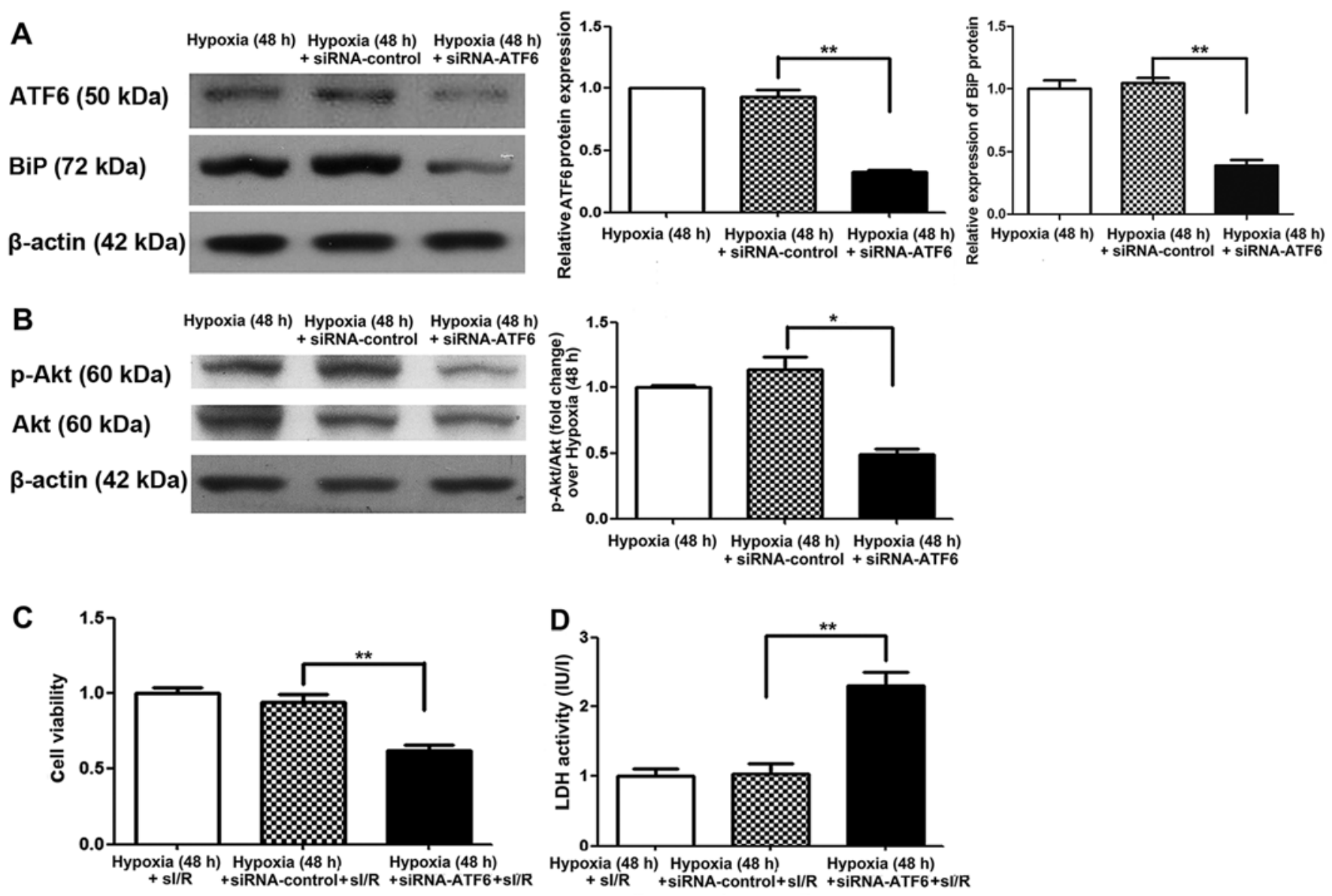

Figure 5. Cleaved activating transcription factor 6 (ATF6) and Akt expression and effects on simulated ischemia/reperfusion (sI/R) injury induced in siRNA-ATF6-transfected H9c2 cells subjected to mild hypoxia. (A) Representative expression of cleaved ATF6 and $\beta$-actin in siRNA-ATF6-transfected H9c2 cells cultured under hypoxic conditions for $48 \mathrm{~h}$ (left); quantification of cleaved ATF6 and binding immunoglobulin protein (BiP) protein levels (normalized to $\beta$-actin protein levels) (right, ${ }^{* *} \mathrm{P}<0.01$ vs. siRNA-control). (B) Representative expression of Akt, $\mathrm{p}$-Akt and $\beta$-actin proteins in siRNA-ATF6-transfected H9c2 cells cultured under hypoxic conditions for $48 \mathrm{~h}$ (left); quantification of p-Akt protein levels (normalized to total Akt protein levels) (right, ${ }^{*} \mathrm{P}<0.05 \mathrm{vs}$. siRNAcontrol). (C) Effect of mild hypoxia on the viability of siRNA-ATF6-transfected H9c2 cells subjected to ischemia (1 h) followed by reperfusion ( $3 \mathrm{~h}$ ). Representative data from five independent experiments are presented as the means \pm SEM ( ${ }^{* *} \mathrm{P}<0.01 \mathrm{vs}$. siRNA-control). (D) Effect of chronic mild hypoxia on lactate dehydrogenase (LDH) activity of siRNA-ATF6-transfected H9c2 cells subjected to ischemia ( $1 \mathrm{~h}$ ) followed by reperfusion ( $3 \mathrm{~h}$ ). Representative data from five independent experiments are presented as the means \pm SEM $(* * 2<0.01$ vs. siRNA-control).

tions are, however, contradicted by opposing studies stating that $\mathrm{CIH}$ inhibits the recovery of left ventricular function and cardioprotection $(27,28)$. To investigate this phenomenon in the present study, rats and $\mathrm{H} 9 \mathrm{c} 2$ cells were exposed to $\mathrm{CIH}$ and their resistance to acute $\mathrm{I} / \mathrm{R}$ injury was evaluated both in vivo and ex vivo. Using these models, $\mathrm{CIH}$ was shown to decrease the cardiac infarct size after I/R. Furthermore, CIH was found to improve the post-ischemic recovery of $\mathrm{LV}$ function in Langendorff rat hearts, as shown by increased LVDP (Fig. 1) and decreased LDH release into the perfusate (Fig. 2), and also to preserve post-I/R cardiac function as assessed by EF or FS and CK-MB activity in an in vivo rat model (Fig. 2). These data suggest that $\mathrm{CIH}$ confers resistance to I/R injury, although the precise mechanism remains to be determined.

$\mathrm{CIH}$ is known to induce local and systemic adaptive responses, including increased blood hemoglobin concentrations, mitochondrial metabolic adaptation (29) and ER stress (30). It has also been shown that chronic hypoxia without reoxygenation upregulates the unfolded protein response in the mouse myocardium (31). ATF6 is activated in response to ER stress, and although some studies demonstrate that ATF6 plays a potentially cardioprotective role (17), other studies have concentrated on the protective effects exerted in acute ischemia $(23,32)$ (such as myocardial infarction) or by mimicking ATF6 activation in transgenic mouse hearts (17). Studies of ATF6 in cardiomyocytes cultured under hypoxic conditions are rare $(30,33)$, and the status of ATF6 activation by $\mathrm{CIH}$ has not been examined either in animals. ATF6 $\alpha$ has been shown to optimize long-term ER function to protect cells against chronic stress (16), and our previous study revealed that hypoxia induced ATF6 and GRP78 expression in primary human cardiomyocytes and $\mathrm{H} 9 \mathrm{c} 2$ cells (18). In the present study, cleaved ATF6 protein expression levels were shown to increase nearly 3 -fold in rat hearts after exposure to $\mathrm{CH}$, with no significant differences being noted between the LV and RV (Fig. 3). Therefore, we hypothesized that ATF6 exerts cardioprotective effects against myocardial I/R injury caused by CIH. To test this hypothesis, we examined cleaved ATF6 expression in $\mathrm{H} 9 \mathrm{c} 2$ cells subjected to mild hypoxia, as previously described (8). Endogenous cleaved ATF6 expression was induced by chronic mild hypoxia in a time-dependent manner, with peak levels detected after $48 \mathrm{~h}$ and maintained up to 
72 h (Fig. 4). Subsequently, we used RNA interference (RNAi) technology to suppress cleaved ATF6 expression in transfected H9c2 cells. After 48 h of exposure to mild hypoxia, cleaved ATF6 was significantly decreased in siRNA-ATF6 transfected H9c2 cells. Furthermore, after 1-h simulated ischemia followed by 3 -h reperfusion (25), CCK-8 analysis showed a significant decrease in siRNA-ATF6-transfected H9c2 cell survival compared with that of siRNA-control-transfected cells, with a concomitant increase in $\mathrm{LDH}$ activity as a marker of cellular necrosis. These observations confirmed that endogenous ATF6 plays a vital, protective role against I/R injury induced by $\mathrm{CIH}$.

The results of the present study in relation to ATF6 expression were supported by investigations into the expression of BiP. BiP is involved in the action of ATF6 and plays an important role in initiating adaptive ER stress and inhibiting apoptotic ER stress (34). Androgen induces BiP to dissociate from ATF6 and act as an androgen receptor-interacting protein, suggesting that $\mathrm{BiP}$ is a regulator of androgen receptor protein quality control (35). Thus, we would expect BiP expression levels to increase with the 50-kDa cleaved form of ATF6. We found that the expression of $\mathrm{BiP}$ in this study was similar to the expression pattern of cleaved ATF6, supporting our hypothesis on the role of ATF6.

The Akt signaling pathway is involved in the regulation of growth, proliferation, protein translation and cell survival in various cell types (36). It has been reported that the ER stress transducer, protein kinase RNA-like ER kinase (PERK) is regulated by phosphorylation mediated by the Akt signaling pathway $(37,38)$. Lin et al (39) demonstrated that Akt is the downstream target of $\mathrm{BiP}$ in mediating cisplatin resistance in ER stress-tolerant human lung cancer cells. Furthermore, a previous study using RNAi technology suggested that Akt activation is associated with the IRE1 $\alpha$ and ATF6 pathways of the ER stress response (40). The activation of ATF6 and PERK contributes to the pro-survival effects of vascular endothelial growth factor on endothelial cells by positively regulating mTORC2-mediated phosphorylation of Akt (23). Collectively, these observations indicate that Akt is regulated by ATF6 in crosstalk between the two signaling pathways; however, there is little reported evidence in relation to the heart. Therefore, based on the results of the present study, we hypothesized that ATF6 is involved in alleviating cardiac I/R damage mediated by $\mathrm{CIH}$ partly through-regulation of the Akt pathway. To test this hypothesis, we also examined Akt expression in H9c2 cell lines subjected to mild hypoxia. We found that endogenous Akt was activated, and the expression of p-Akt increased, which is consistent with previous findings (30). Similarly, after $48 \mathrm{~h}$ of exposure to mild hypoxia, p-Akt levels were significantly suppressed in siRNA-ATF6-transfected H9c2 cells compared with those transfected with the siRNA-control. These data indicate that ATF6 contributes to cardioprotection by regulating p-Akt. Akt is activated by the phosphorylation of Thr308 and Ser473. Activated Akt exerts cardioprotective effects by phosphorylating multiple targets in the cytoplasm, nucleus, mitochondria and on the surface of the ER membrane, including glycogen synthase kinase-3 $\beta$ (41), cardiac mTOR (3), nuclear factor- $\kappa \mathrm{B}(42)$, the pro-apoptotic $\mathrm{Bcl}-2$ family member BAD (43) and caspase-9 (44). However, the detailed mechanism by which ATF6 regulates Akt remains to be clarified.
In conclusion, using in vivo and ex vivo models, we have demonstrated for the first time to the best of our knowledge, that $\mathrm{CIH}$ protects the myocardium from I/R injury by upregulating ATF6 through a mechanism potentially involving the Akt pathway. These observations likely explain the mechanism underlying the low morbidity rate of patients with chronic ischemic heart disease and the lower rate of mortality due to myocardial infarction in populations living at high altitudes (1), which is consistent with our clinical observations. Furthermore, ATF6 has been implicated as a molecular target in interventions aimed at alleviating $I / R$ injury in patients experiencing a cardiovascular event.

\section{Acknowledgements}

This study was supported by the National Natural Science Foundation of China (nos. 81270228 and 81370004).

\section{References}

1. Faeh D, Gutzwiller F and Bopp M; Swiss National Cohort Study Group: Lower mortality from coronary heart disease and stroke at higher altitudes in Switzerland. Circulation 120: 495-501, 2009.

2. Hu Y, Sun Q, Li Z, Chen J, Shen C, Song Y and Zhong Q: High basal level of autophagy in high-altitude residents attenuates myocardial ischemia-reperfusion injury. J Thorac Cardiovasc Surg 148: 1674-1680, 2014.

3. Neckár J, Papousek F, Nováková O, Ost'ádal B and Kolár F: Cardioprotective effects of chronic hypoxia and ischaemic preconditioning are not additive. Basic Res Cardiol 97: 161-167, 2002.

4. Naghshin J, McGaffin KR, Witham WG, Mathier MA Romano LC, Smith SH, Janczewski AM, Kirk JA, Shroff SG and O'Donnell CP: Chronic intermittent hypoxia increases left ventricular contractility in C57BL/6J mice. J Appl Physiol 107: 787-793, 2009.

5. Naghshin J, Rodriguez RH, Davis EM, Romano LC, McGaffin KR and O'Donnell CP: Chronic intermittent hypoxia exposure improves left ventricular contractility in transgenic mice with heart failure. J Appl Physiol 113: 791-798, 2012.

6. Asemu G, Papousek F, Ostádal B and Kolár F: Adaptation to high altitude hypoxia protects the rat heart against ischemia-induced arrhythmias. Involvement of mitochondrial K(ATP) channel. J Mol Cell Cardiol 31: 1821-1831, 1999.

7. Borchert GH, Yang C and Kolár F: Mitochondrial BKCa channels contribute to protection of cardiomyocytes isolated from chronically hypoxic rats. Am J Physiol Heart Circ Physiol 300: H507-H513, 2011.

8. Crawford RM, Jovanović S, Budas GR, Davies AM, Lad H, Wenger RH, Robertson KA, Roy DJ, Ranki HJ and Jovanović A: Chronic mild hypoxia protects heart-derived H9c2 cells against acute hypoxia/reoxygenation by regulating expression of the SUR2A subunit of the ATP-sensitive $\mathrm{K}^{+}$channel. J Biol Chem 278: 31444-31455, 2003.

9. Kolár F, Jezková J, Balková P, Breh J, Neckár J, Novák F, Nováková $\mathrm{O}$, Tomásová $\mathrm{H}$, Srbová $\mathrm{M}$, Ostádal $\mathrm{B}$, et al: Role of oxidative stress in PKC-delta upregulation and cardioprotection induced by chronic intermittent hypoxia. Am J Physiol Heart Circ Physiol 292: H224-H230, 2007.

10. Baker JE, Holman P, Kalyanaraman B, Griffith OW and Pritchard KA Jr: Adaptation to chronic hypoxia confers tolerance to subsequent myocardial ischemia by increased nitric oxide production. Ann NY Acad Sci 874: 236-253, 1999.

11. Morel S, Milano G, Ludunge KM, Corno AF, Samaja M, Fleury S, Bonny C, Kappenberger L, von Segesser LK and Vassalli G: Brief reoxygenation episodes during chronic hypoxia enhance posthypoxic recovery of LV function: role of mitogen-activated protein kinase signaling pathways. Basic Res Cardiol 101: 336-345, 2006.

12. Strnisková M, Ravingerová T, Neckár J, Kolár F, Pastoreková S and Barancík M: Changes in the expression and/or activation of regulatory proteins in rat hearts adapted to chronic hypoxia. Gen Physiol Biophys 25: 25-41, 2006. 
13. Bianciardi P,Fantacci M, Caretti A, Ronchi R, Milano G, Morel S, von Segesser L, Corno A and Samaja M: Chronic in vivo hypoxia in various organs: hypoxia-inducible factor-1alpha and apoptosis. Biochem Biophys Res Commun 342: 875-880, 2006.

14. Kakinuma Y, Tsuda M, Okazaki K, Akiyama T, Arikawa M, Noguchi T and Sato T: Heart-specific overexpression of choline acetyltransferase gene protects murine heart against ischemia through hypoxia-inducible factor- $1 \alpha$-related defense mechanisms. J Am Heart Assoc 2: e004887, 2013.

15. Belmont PJ, Tadimalla A, Chen WJ, Martindale JJ, Thuerauf DJ, Marcinko M, Gude N, Sussman MA and Glembotski CC: Coordination of growth and endoplasmic reticulum stress signaling by regulator of calcineurin 1 (RCAN1), a novel ATF6-inducible gene. J Biol Chem 283: 14012-14021, 2008.

16. Wu J, Rutkowski DT, Dubois M, Swathirajan J, Saunders T, Wang J, Song B, Yau GD and Kaufman RJ: ATF6alpha optimizes long-term endoplasmic reticulum function to protect cells from chronic stress. Dev Cell 13: 351-364, 2007.

17. Martindale JJ, Fernandez R, Thuerauf D, Whittaker R, Gude N, Sussman MA and Glembotski CC: Endoplasmic reticulum stress gene induction and protection from ischemia/reperfusion injury in the hearts of transgenic mice with a tamoxifen-regulated form of ATF6. Circ Res 98: 1186-1193, 2006.

18. Jian Z, Li JB, Ma RY, Chen L, Wang XF and Xiao YB: Pivotal role of activating transcription factor $6 \alpha$ in myocardial adaptation to chronic hypoxia. Int J Biochem Cell Biol 44: 972-979, 2012.

19. Fujio Y, Nguyen T, Wencker D, Kitsis RN and Walsh K: Akt promotes survival of cardiomyocytes in vitro and protects against ischemia-reperfusion injury in mouse heart. Circulation 101: 660-667, 2000

20. Jacinto E, Facchinetti V, Liu D, Soto N, Wei S, Jung SY, Huang Q, Qin J and Su B: SIN1/MIP1 maintains rictor-mTOR complex integrity and regulates Akt phosphorylation and substrate specificity. Cell 127: 125-137, 2006.

21. Cai Z and Semenza GL: Phosphatidylinositol-3-kinase signaling is required for erythropoietin-mediated acute protection against myocardial ischemia/reperfusion injury. Circulation 109: 2050-2053, 2004.

22. Matsui T, Tao J, del Monte F, Lee KH, Li L, Picard M, Force TL, Franke TF, Hajjar RJ and Rosenzweig A: Akt activation preserves cardiac function and prevents injury after transient cardiac ischemia in vivo. Circulation 104: 330-335, 2001.

23. Karali E, Bellou S, Stellas D, Klinakis A, Murphy C and Fotsis T: VEGF Signals through ATF6 and PERK to promote endothelial cell survival and angiogenesis in the absence of ER stress. Mol Cell 54: 559-572, 2014

24. Gardner BM, Pincus D, Gotthardt K, Gallagher CM and Walter P: Endoplasmic reticulum stress sensing in the unfolded protein response. Cold Spring Harb Perspect Biol 5: a013169, 2013.

25. Ren XP, Wu J, Wang X, Sartor MA, Qian J, Jones K, Nicolaou P, Pritchard TJ and Fan GC: MicroRNA-320 is involved in the regulation of cardiac ischemia/reperfusion injury by targeting heat-shock protein 20. Circulation 119: 2357-2366, 2009.

26. Fujii Y, Ishino K, Tomii T, Kanamitsu H, Mitsui H and Sano S: Tolerance of the developing cyanotic heart to ischemia-reperfusion injury in the rat. Gen Thorac Cardiovasc Surg 58: 174-181, 2010.

27. Joyeux-Faure M, Stanke-Labesque F, Lefebvre B, Beguin P, Godin-Ribuot D, Ribuot C, Launois SH, Bessard G and Levy P: Chronic intermittent hypoxia increases infarction in the isolated rat heart. J Appl Physiol 98: 1691-1696, 2005.

28. Milano G, Corno AF, Samaja M, Morel S, Vassalli G and von Segesser LK: Daily reoxygenation decreases myocardial injury and improves post-ischaemic recovery after chronic hypoxia. Eur J Cardiothorac Surg 37: 942-949, 2010.
29. Heather LC, Cole MA, Tan JJ, Ambrose LJ, Pope S, Abd-Jamil AH, Carter EE, Dodd MS, Yeoh KK, Schofield CJ and Clarke K: Metabolic adaptation to chronic hypoxia in cardiac mitochondria. Basic Res Cardiol 107: 268, 2012.

30. Thuerauf DJ, Marcinko M, Gude N, Rubio M, Sussman MA and Glembotski CC: Activation of the unfolded protein response in infarcted mouse heart and hypoxic cultured cardiac myocytes. Circ Res 99: 275-282, 2006.

31. Tagliavacca L, Caretti A, Bianciardi P and Samaja M: In vivo up-regulation of the unfolded protein response after hypoxia. Biochim Biophys Acta 1820: 900-906, 2012.

32. Doroudgar S, Thuerauf DJ, Marcinko MC, Belmont PJ and Glembotski CC: Ischemia activates the ATF6 branch of the endoplasmic reticulum stress response. J Biol Chem 284: 29735-29745, 2009.

33. Terai K, Hiramoto Y, Masaki M, Sugiyama S, Kuroda T, Hori M, Kawase I and Hirota H: AMP-activated protein kinase protects cardiomyocytes against hypoxic injury through attenuation of endoplasmic reticulum stress. Mol Cell Biol 25: 9554-9575, 2005.

34. Wang L, Tang W, Jiang T, Lu P, Li Y, Sun A, Shen Y, Chen Y, Wang H, Zong Z, et al: Endoplasmic reticulum stress is involved in the neuroprotective effect of propofol. Neurochem Res 39: 1741-1752, 2014.

35. Yang YC, Fu HC, Hsiao BL, Sobue G, Adachi H, Huang FJ, Hsuuw YD, Wei KT, Chang C, Huang KE and Kang HY: Androgen receptor inclusions acquire GRP78/BiP to ameliorate androgen-induced protein misfolding stress in embryonic stem cells. Cell Death Dis 4: e607, 2013.

36. Song G, Ouyang G and Bao S: The activation of Akt/PKB signaling pathway and cell survival. J Cell Mol Med 9: 59-71, 2005.

37. Blaustein M, Pérez-Munizaga D, Sánchez MA, Urrutia C, Grande A, Risso G, Srebrow A, Alfaro J and Colman-Lerner A: Modulation of the Akt pathway reveals a novel link with PERK/ eIF2 $\alpha$, which is relevant during hypoxia. PLoS One 8: e69668, 2013.

38. Hu P, Han Z, Couvillon AD and Exton JH: Critical role of endogenous Akt/IAPs and MEK1/ERK pathways in counteracting endoplasmic reticulum stress-induced cell death. J Biol Chem 279: 49420-49429, 2004

39. Lin Y, Wang Z, Liu L and Chen L: Akt is the downstream target of GRP78 in mediating cisplatin resistance in ER stress-tolerant human lung cancer cells. Lung Cancer 71: 291-297, 2011.

40. Jiang CC, Yang F, Thorne RF, Zhu BK, Hersey P and Zhang XD: Human melanoma cells under endoplasmic reticulum stress acquire resistance to microtubule-targeting drugs through XBP-1-mediated activation of Akt. Neoplasia 11: 436-447, 2009.

41. Zhang Y, Xia Z, La Cour KH and Ren J: Activation of Akt rescues endoplasmic reticulum stress-impaired murine cardiac contractile function via glycogen synthase kinase- $3 \beta$-mediated suppression of mitochondrial permeation pore opening. Antioxid Redox Signal 15: 2407-2424, 2011.

42. Romashkova JA and Makarov SS: NF-kappaB is a target of AKT in anti-apoptotic PDGF signalling. Nature 401: 86-90, 1999.

43. Aikawa R, Nawano M, Gu Y, Katagiri H, Asano T, Zhu W, Nagai R and Komuro I: Insulin prevents cardiomyocytes from oxidative stress-induced apoptosis through activation of PI3 kinase/Akt. Circulation 102: 2873-2879, 2000.

44. Cardone MH, Roy N, Stennicke HR, Salvesen GS, Franke TF, Stanbridge E, Frisch S and Reed JC: Regulation of cell death protease caspase-9 by phosphorylation. Science 282: 1318-1321, 1998. 